\title{
A YEAR OF CARDIO-RESPIRATORY RESUSCITATION
}

\author{
Experience with the AMSET \\ Major C. K. DAVIES, M.A., B.M., B.Ch., F.F.A.R.C.S., R.A.M.C. \\ Cambridge Military Hospital, Aldershot
}

SUMMARY: The results of one year's experience with the AMSET in the Cambridge Military Hospital, are described. There were 15 cases of cardiac arrest; though normal rhythm was restored in 3 of these, none of them eventually survived. There were 10 cases of respiratory insufficiency, occurring in 9 patients, of whom 2 eventually recovered. The significance of these results is discussed, together with some practical points concerning the optimum use of the trolley. It is concluded that the AMSET has a valuable part to play in any military hospital.

The development of the Army Medical Services Emergency Trolley (AMSET) has been outlined by Hunt and Hutton (1962) and Hunt (1966). The AMSET is intended for the immediate treatment of cardiac arrest, respiratory insufficiency and severe shock. During the period covered by this review, there was only one AMSET in the hospital; it was housed on Ward 8, which at that time filled the multiple roles of admission, observation and resuscitation ward, post-operative recovery ward, and intensive therapy unit. Any ward or department requiring the AMSET summoned it by calling the hospital switchboard on a "hot line". The operator informed Ward 8, and then contacted the duty anaesthetist and either the casualty officer or the orderly medical officer, depending on the time of day. Meanwhile, the appropriate first-aid measures such as external cardiac compression and expired-air ventilation were instituted. (The present procedure is similar, except that the main medical ward and the casualty department now have their own AMSETs).

\section{Material and methods}

During the year under review, from 10 July 1966 to 9 July 1967, users of the AMSET were asked to record each patient's name on a millboard attached to the trolley. The author was then able to obtain further details from the case-notes and from the doctors concerned. While this procedure seems to have been followed for cases of cardiac arrest and respiratory insufficiency, it was noted about half-way through the survey that no case of severe shock had been recorded. Enquiry of the ward staff revealed that there had been at least three such cases, for which AMSET transfusion equipment had been used; all of these cases had been on Ward 8 itself. Presumably those concerned did not regard transfusion, even emergency transfusion, as worth recording; the necessary equipment is not particularly specialised, and is readily available in most wards and departments. Because of the incomplete data for severe shock, only cardiac arrest and respiratory insufficiency are considered in this paper.

The AMSET was used for 25 such emergencies, occurring in 22 patients. To prevent confusion the word case is used hereafter to refer to any single use of the AMSET, while the word patient will signify an individual person, however many times he required the AMSET. 
Types of emergency

Of the 25 cases, 15 were cardiac arrest, and 10 were respiratory insufficiency (Table I). Of the cardiac arrest cases, seven were asystole, three ventricular fibrillation,

Table I

Types of emergency

\begin{tabular}{l|c|l|c}
\multicolumn{1}{c|}{ Cardiac arrest } & Number & \multicolumn{1}{c|}{ Respiratory insufficiency } & Number \\
\hline Asystole & 7 & Obstruction & 4 \\
Ventricular fibrillation & 3 & Central depression & 4 \\
Heart block & 1 & Stove-in chest & 2 \\
Unknown & 4 & & \\
\hline Totals & 15 & & 10 \\
\hline
\end{tabular}

and one complete heart block with severe ventricular depression. In the remaining four, the nature of the arrhythmia is unknown, either because it was not recorded or because normal rhythm had been restored by the time an e.c.g. tracing was obtained. Of the respiratory cases, four were obstructive in nature (due to blood or vomitus), four were due to central depression, and two were due to stove-in chest.

\section{Procedures}

The commonest procedures were endotracheal intubation, intermittent positivepressure ventilation (I.P.P.V.) using the Mapleson C assembly provided, electrocardiography, and the administration of a variety of drugs. Other procedures were external a.c. defibrillation, external pacemaking, intravenous infusion, and bronchoscopy, while in one case only the insertion of an oro-pharyngeal airway was required. The frequency with which these procedures were carried out is shown in Table II.

Table II

Procedures carried out in 25 cases

\begin{tabular}{l|c|l|c}
\hline \multicolumn{1}{c|}{ Procedure } & Number & Procedure & Number \\
\hline Endotracheal intubation & 19 & Defibrillation & 4 \\
Intermittent positive-pressure ventilation & 15 & Pacemaker & 4 \\
Electrocardiography & 13 & Bronchoscopy & 2 \\
Drugs & 13 & Airway & 1 \\
Intravenous infusion & 6 & & \\
\hline
\end{tabular}

\section{Drugs}

In Table III are shown details of the drugs used: in most cases these were already on the AMSET, but occasionally it was necessary to send for drugs from other sources. 
Table III

Drugs used in 13 cases

\begin{tabular}{l|c|l|r}
\hline \multicolumn{1}{c|}{ Drugs on AMSET } & Number & \multicolumn{1}{|c}{ Drugs not on AMSET } & Number \\
\hline Sodium bicarbonate & 8 & Suxamethonium & 2 \\
Calcium salts & 4 & Urea & 1 \\
Adrenaline & 4 & Lignocaine & 1 \\
Metaraminol & 2 & Frusemide & 1 \\
Mannitol & 2 & Sorbitol & 1 \\
\hline
\end{tabular}

\section{Patients}

Of the 22 patients, 13 were male and 9 female. Of these, one male and two females required the AMSET twice. Six patients were service personnel, two were dependents of servicemen, while the majority, fourteen, were civilians. Ages ranged from 6 to 77 years. The principal diseases from which the patients were suffering are listed in Table IV, which shows the predominance of trauma.

Table IV

Disease groups

\begin{tabular}{l|c|l|c}
\hline \multicolumn{1}{c|}{ Traumatic } & Number & \multicolumn{1}{c|}{ Non-traumatic } & Number \\
\hline $\begin{array}{l}\text { Severe head injury } \\
\text { Multiple injuries }\end{array}$ & 3 & Cardiac infarction & 5 \\
Chest injury & 4 & Pulmonary embolus & 2 \\
Other trauma & 2 & Miscellaneous & 3 \\
\hline Totals & 3 & & 10 \\
\hline
\end{tabular}

\section{Location of emergencies.}

Twenty-two cases occurred in Ward 8 itself, one in a general surgical ward, one in in the X-ray department, and one in Casualty. These figures may be a little misleading in that they obscure the fact that many of the cases dealt with on Ward 8 had been admitted there directly, without stopping in Casualty. At the time the Casualty Department was somewhat inadequate (it has since been rebuilt) and as Ward 8 was situated close by it was usual for serious cases to be dealt with in this way. In most hospitals it is likely that 10 cases would have been treated in Casualty.

\section{Outside cases}

In addition to the cases already described, on two occasions an external defibrillator from the AMSET was sent to a civilian hospital in response to an urgent request. On each occasion a member of the anaesthetic staff provided assistance and advice.

\section{Results}

It is not as easy to assess results in this type of emergency treatment as might be supposed, for if a patient who has suffered an anoxic incident does not die, his final state may vary from complete recovery, through slight disablement, to survival in a permanently unconscious state. The degree of success will depend not only on the 
efficiency of the treatment, but also on the nature and severity of the underlying disease process. In this series two criteria of success have been applied: immediate success and final survival. By immediate success is meant that the basic object of summoning the AMSET was achieved, for cardiac arrest the restoration of cardiac action compatible with life, and for respiratory insufficiency the restoration of adequate ventilation, either spontaneous or artificial. By final survival is meant that the patient was discharged from hospital, even if in a disabled state.

\section{Overall results}

In the 22 patients ( 25 cases), final survival was achieved in only two (three cases). Both patients made good clinical recoveries. Immediate success was obtained in 10 cases out of 25 . Of the three patients requiring the AMSET twice, immediate success was obtained once in one patient and twice in the other two, but only one of the latter reached final survival.

Of the two outside cases, immediate success was obtained in one, final survival in neither. These two cases will not be considered further.

\section{Results in different types of emergency}

These are shown in Table V. Of the 15 cases of cardiac arrest, occurring in the

Table $\mathrm{V}$

Results in different types of emergency

\begin{tabular}{l|c|c|c}
\multicolumn{1}{c|}{ Emergency } & Number & Immediate success & Final survival \\
\hline $\begin{array}{l}\text { Cardiac arrest } \\
\text { Respiratory insufficiency }\end{array}$ & $\begin{array}{l}15(15) \\
10(9)\end{array}$ & $\begin{array}{l}3(3) \\
7(6)\end{array}$ & $3(2)$ \\
\hline
\end{tabular}

Note: First figure gives number of cases, figure in parentheses gives number of patients. Total number of patients here appears to be 24 instead of 22 , because 2 patients had one emergency of each type.

same number of patients, the heart was restored to normal rhythm in only 3 . Of these two were ventricular fibrillation, and one was of unknown type, the heart having been restarted by external cardiac compression before an e.c.g. record was obtained. All three died later.

Of the 10 cases of respiratory insufficiency, occurring in 9 patients, adequate ventilation was obtained in 7 cases ( 6 patients). Only 3 cases ( 2 patients) survived. Thus the only final survivals were in the respiratory group.

\section{Results}

\section{Discussion}

There have been several reports in the literature of the results of resuscitation services. Sykes and Ahmed (1963) described 185 cardiac arrests in 161 patients over a three-year period at Hammersmith, while Sykes and Orr (1966) described 203 arrests in 184 patients in a later two-year period at the same hospital. In these two series the final survival rates were 13.1 per cent and 20.6 per cent. Marshall (1966) gave an account of a year's work by the service at St. Bartholomew's Hospital, where there were over 130 arrests in 83 patients, of whom 14.5 per cent were discharged from hospital. The 
results in the present paper, with no survivals out of 15 patients suffering cardiac arrest, may appear at first sight to be very discouraging. However, if the survival figures of the three previous series quoted are added together and compared with the present series the difference is not significant $(P=0.1)$. Furthermore, the present series includes five cases where the arrest occurred before admission to hospital, and in three of these (20 per cent of the total) the patients were considered clinically dead on arrival, resuscitation being attempted only as a matter of routine pending more careful assessment. It is not known what proportion of the arrests in the Hammersmith and St. Bartholomew's series fell into this category, though it was probably considerably lower. (There is support for this belief in the figures given by Sykes and Orr (1966) for place of arrest.).

The fact that no patient in this series survived cardiac arrest should not, therefore, lead one to dismiss the AMSET as valueless in such cases. There have been survivals, though not during the relatively short period considered here.

On the other hand, it is worth noting that in one case the heart returned to normal rhythm before the AMSET arrived, and though this case appears in Table V as one of the "immediate successes", no credit is due to the AMSET for this. The only part played by the AMSET was to provide e.c.g. confirmation of the normal rhythm. (That this patient really did have cardiac arrest was substantiated by the fact that within the hour his heart stopped again, this time permanently). Another reason for mentioning this case is that it illustrates the important point that the AMSET is not an item of first-aid equipment. The first-aid equipment for cardiac arrest comprises a pair of hands and a mouth.

Of the respiratory emergencies, little need be said. Out of nine patients, two lived who would otherwise have died.

\section{Equipment}

The trolley itself is large and heavy compared with types in use in some other hospitals. While it is not so unwieldly that its mobility is seriously impaired, it could with benefit be considerably smaller. When existing trolleys eventually require replacement, their successors should be designed with this in mind.

Associated with the large size is the tendency for the AMSET to become overstocked with equipment and drugs. Each time it is used, someone thinks of something that could be added, and unless this process is carefully controlled the drawers and compartments become so full that vital items are difficult to find. On the other hand, the approach must be flexible, so that new items of genuine value can be added from time to time. For example, our experience here has suggested that suxamethonium should be carried.

At the beginning of this paper, it was suggested that the AMSET was not generally regarded as playing an important part in emergency intravenous infusion. This does not mean that drip-sets, cut-down sets and the like should not be carried, for they are essential adjuncts to the treatment of cardiac and respiratory arrest. However, intravenous fluids are quite bulky and overstocking is often allowed to occur. The original description by Hunt and Hutton (1962) listed no less than 13 litres, including 3 litres of Dextran. It is still common to carry Dextran 110 , which is rarely used in view of its 
known disadvantages and the ready availability of blood in most military hospitals. Dextran 70 would be of much greater value.

Considerable trouble has been experienced with the "Cardette" elctrocardiograph. Though small, easily operated and eminently portable, it suffers from the grave disadvantage that (in common with other models) it is easily put away while still switched on. Consequently, the battery discharges itself and when next required the machine is useless. It would be a simple matter to modify the machine in such a way that the lid could not be replaced until the main switch was in the "off" position; this possibility has been discussed with the makers.

Apart from the virtues or otherwise of this particular apparatus, the AMSET would be better served by an oscilloscope with recording facilities, and it is understood that a cardiograph of this type is to be supplied in the not too distant future.

Every AMSET requires constant supervision and checking, to ensure that equipment remains in working order, and that expendable items are replenished. The officer responsible for each AMSET must be designated by name. In addition, a more general supervision is needed, to ensure that new developments in cardio-respiratory resuscitation techniques are considered, and the contents of AMSETs modified from time to time. Such supervision is most satisfactorily carried out by the anaesthetics department, in consultation with other interested parties.

\section{Training}

The AMSET is useless unless staff are trained to use it. At this hospital a series of lecture-demonstrations is given by an anaesthetist two or three times each year. Each time, the same lecture is given every day for a week, so that a large proportion of the hospital staff can attend once in each series.

Endotracheal intubation is a procedure of which all medical officers and State Registered Nurses should be capable in an emergency. Instruction in this technique is therefore given whenever the opportunity presents.

\section{Role of the AMSET}

The AMSET provides a compact, mobile set of equipment for the treatment of cardiac and respiratory emergencies anywhere in the hospital. It seems curious to look back only six years to find the AMSET recommended as an alternative to a recovery ward (Hunt and Hutton, 1962). No one today denies the value of such a ward, and no modern hospital is without one. Yet this does not make the AMSET redundant, for a recovery ward is basically just a room, in convenient proximity to the operating theatre. The room needs expensive and bulky equipment, which must be moved around, and the simplest way to move it is by a trolley. Such a trolley is an AMSET. So far from being a replacement for a recovery ward, therefore, an AMSET is a useful and almost essential component of such a ward. A similar arguement applies to the rest of the hospital, and the only problem to be decided is the number and distribution of AMSETs; this will depend on the geography and work-load of each hospital considered.

MARShaLl, R. D. (1966). Anaesthesia 21, 86

\section{REFERENCES}

HUNT, R. S. (1966). J. roy. Army med. Cps. 112, 58.

Hunt, R. S. and Hutton, D. S. (1962). J. roy. Army med. Cps. 108, 35.

SYKES, M. K. and AHMED, N. (1963). Lancet $i$, 347.

SYKES, M. K. and ORR, D. S. (1966). Anaesthesia 21, 363. 